cerebral artery infarcts.

LATE PROGRESSIVE THALAMIC ATROPHY in four children with neonatal middle cerebral artery infarction is reported from the Centre Hospitalo-Universitaire, Dijon, France. (Giroud M, Dumas R et al. Child's Nerv Syst March 1995;11:133-136).

\title{
DEVELOPMENTAL DELAY AFTER HEART SURGERY
}

The developmental and neurologic status of 155 children were evaluated one year after heart surgery for D-transposition of the great arteries, comparing those randomly assigned to circulatory arrest or low-flow cardiopulmonary bypass, at Children's Hospital, Boston, MA. Circulatory arrest was associated with lower scores on the Bayley Scales of Infant Development, and the Psychomotor Development Index was inversely related to the duration of circulatory arrest. Risk of neurologic abnormalities also increased with the duration of circulatory arrest. A ventricular septal defect, present in 35 (23\%), and seizure activity detected by continuous EEG monitoring in the early postoperative period were independent risk factors for a poor outcome. MRI abnormalities, and mental development and visual memory test scores were not correlated with the method of circulatory support. (Bellinger DC, Newburger JW et al. Developmental and neurologic status of children after heart surgery with hypothermic circulatory arrest or low-flow cardiopulmonary bypass. N Engl I Med March 2, 1995;332:549-55). (Reprints: Dr Newburger, Department of Cardiology, Children's Hospital, 300 Longwood Ave, Boston, MA 02115).

COMMENT. This report is a follow up of the perioperative neurologic effects of hypothermic circulatory arrest compared to low-flow cardiopulmonary bypass in 171 patients operated within the first three months of age at the Children's Hospital, Boston. (Newburger JW et al. $\underline{\mathrm{N}}$ Engl I Med 1993;329:1057-64). Circulatory arrest was associated with a higher incidence of clinical and EEG seizures in the first 6 hours after surgery, but the incidence of neurologic abnormalities was similar in the two groups at time of discharge. (See Progress in Pediatric Neurology II, 1994, p386). It now appears that the technical advantages of total circulatory arrest may be outweighed by delayed motor development and neurologic abnormalities at one year and potential cognitive deficits at school age.

NEURODEVELOPMENTAL OUTCOME OF 11 INFANTS WITH SURGERY FOR HYPOPLASTIC LEFT HEART SYNDROME is reported from the State University of New York and Children's Hospital of Buffalo. (Rogers BT et al. I Pediatr March 1995;126:496-8). Testing at a mean age of 38 months showed microcephaly in $8(73 \%)$, mental retardation in $7(64 \%)$, gross motor delays in $5(45 \%)$, and severe cerebral palsy in $2(18 \%)$. The quality of life is obviously seriously impaired in these patients, a factor to be considered in treatment options.

\section{BREATH-HOLDING SPELLS AND ANEMIA}

Two children, ages 32 months and 19 months, with breath-holding spells that resolved after treatment for concomitant anemia, are reported from the 
University of Washington School of Medicine and the Children's Hospital, Seattle. One child with B-thalassemia trait had a hemoglobin of $48 \mathrm{gm} / \mathrm{L}$, hematocrit 0.15 , and ferritin $42 \mathrm{ng} / \mathrm{ml}$. The second patient with a cor triatriatum had a hemoglobin of $51 \mathrm{gm} / \mathrm{L}$, hematocrit 0.18 , and ferritin 3 $\mathrm{ng} / \mathrm{ml}$ (normal, $15-160 \mathrm{ng} / \mathrm{ml}$ ). Patient 1 was treated with an erythrocyte transfusion, and patient 2 received oral iron. (Colina KF, Abelson HT. Resolution of breath-holding spells with treatment of concomitant anemia. I Pediatr March 1995;126:395-7). (Reprints: Kenneth F Colina MD, Scott and White Clinic, 7700 Fish Pond Rd, Waco, TX 76710).

COMMENT. The association between breath-holding spells and anemia was first reported by Holowach J and Thurston DL. (N Engl I Med $1963 ; 268: 21-3)$. Iron deficiency anemia was noted in $23 \%$ of cases.

Reversible focal neurologic deficits were reported in a 14 year old female adolescent with severe iron deficiency anemia and bleeding from intestinal polyposis and hemorrhagic telangiectasia. (Bruggers CS et al. I Pediatr 1990;117:430). After transfusion with packed erythrocytes and treatment with oral ferrous sulfate, facial palsy resolved within 12 hours and a VI nerve palsy and somnolence cleared by the fifth day. A syncopal episode was not repeated. (See Progress in Pediatric Neurology I, 1991, p397-8).

IRON DEFICIENCY AND INFANT DEVELOPMENT is addressed in an editorial (Lozoff B. L Pediatr Oct 1994;125:577-8). Moffatt and colleagues reported in this issue of the journal that iron deficiency caused lower developmental test scores in infancy. Iron therapy resulted in an increase of 30 points in mental scores and 24 points in motor scores in a double-blind, randomized, placebo-controlled trial conducted in Indonesia. The prevention of iron deficiency anemia during the first few years of life is important to assure optimal neurodevelopmental outcome and the avoidance of breath-holding spells.

\section{BRAIN TRAUMA}

\section{LONG-TERM OUTCOME AFTER SEVERE BRAIN INJURY}

The outcome in adulthood of severe brain injury in 39 preschoolers, aged 7 years or less, was evaluated at the Kauniala Hospital for Disabled War Veterans, the Rehabilitation Centre of Insurance Companies, Kauniainen, and the University of Helsinki, Finland. Twenty three (59\%) attended a typical school, $8(21 \%)$ attended a school for the physically disabled, and 7 (18\%) attended school for the mentally retarded. In adulthood, 9 patients $(23 \%)$ worked full-time, 10 (26\%) worked at sheltered work-places, 14 (36\%) lived independently at home, and 6 (15\%) needed physical or psychological support. Of the 23 who attended a normal school in childhood, only 9 were capable of full-time work as adults. A sense of identity was the best indicator of final outcome. (Koskiniemi M et al. Long-term outcome after severe brain injury in preschoolers is worse than expected. Arch Pediatr Adolesc Med March 1995;149:249-254). (Respond: Mr Taina Nybo, Kauniala Hospital for Disabled War Veterans, 02700 Kauniainen, Finland).

COMMENT. The long-term outcome was worse than expected from initial 